
Technologies

\title{
Optimization of TLC Method for Separation and Determination of Ziprasidone and Its Impurities
}

\section{Darija Obradović, Slavica Filipić, Katarina Nikolić, Marija Čarapić \& Danica} Agbaba

To cite this article: Darija Obradović, Slavica Filipić, Katarina Nikolić, Marija Čarapić \& Danica Agbaba (2016): Optimization of TLC Method for Separation and Determination of Ziprasidone and Its Impurities, Journal of Liquid Chromatography \& Related Technologies, DOI: 10.1080/10826076.2016.1163183

To link to this article: http://dx.doi.org/10.1080/10826076.2016.1163183

Accepted author version posted online: 10

Mar 2016.

Submit your article to this journal $๘$

View related articles \lceil

View Crossmark data $₫$ 


\title{
Optimization of TLC Method for Separation and Determination of Ziprasidone and Its Impurities
}

Darija Obradović ${ }^{1}$, Slavica Filipić ${ }^{1}$, Katarina Nikolić $^{1}$, Marija Čarapić ${ }^{2}$, Danica Agbaba ${ }^{1}$

${ }^{1}$ University of Belgrade, Faculty of Pharmacy, Department of Pharmaceutical Chemistry, Belgrade, Serbia, ${ }^{2}$ Medicines and Medical Devices Agency of Serbia, Belgrade, Serbia

Address correspondence to Danica Agbaba, Department of Pharmaceutical Chemistry, Faculty of Pharmacy, University of Belgrade, Vojvode Stepe 450, 11000 Belgrade,

Serbia. E-mail: danica@ pharmacy.bg.ac.rs

\begin{abstract}
A thin-layer chromatographic method for simultaneous determination of ziprasidone and its main impurities was developed and validated. Separation of the examined compounds was performed on chromatographic plates precoated with silica gel $60 \mathrm{~F}_{254}$ and using toluene-methanol-glacial acetic acid, 7.5:0.5:0.5 (v/v/v) as mobile phase. Ascending development mode was performed in the twin-trough chromatographic chamber, which was presaturated with mobile phase vapors for $15 \mathrm{~min}$. The developed chromatographic plates were dried in air and densitometrically scanned at the wavelengths of 250 and 320 $\mathrm{nm}$. Regression coefficient $(r \geq 0.992)$, recovery (94.94-106.70\%), limit of quantification of impurities ( $25 \mathrm{ng} \mathrm{band}^{-1}$ equivalent to the $0.14 \%$ impurity level), and robustness were validated and found satisfactory. The developed method is convenient for quantitative analysis and the purity screening of ziprasidone in pharmaceutical formulations.

KEYWORDS: impurities, method validation, ziprasidone, quantitation, TLC, pharmaceuticals
\end{abstract}

\section{INTRODUCTION}


Ziprasidone (ZP) belongs to the second generation of so-called atypical antipsychotic drugs, having the G protein-coupled receptor (GPCR) binding profile. It is a high-affinity antagonist at $5-\mathrm{HT}_{2 \mathrm{~A}}, 5-\mathrm{HT}_{2 \mathrm{C}}$ and $\mathrm{D}_{2}$ as well as at adrenergic $\alpha_{1} / \alpha_{2}$ and histamine $\mathrm{H} 1$ receptors. It is used for the treatment of schizophrenia and bipolar disorders, with relatively low incidence of extrapyramidal side effects. ${ }^{[1,2]}$

Ziprasidone is a benzisothiazolyl piperazine compound that exists as a white crystalline solid with a very poor aqueous solubility. The $\mathrm{pKa}$ a values of the two ionisable functional groups in the molecule are 8.4 and 13.3, respectively. Even after having been on the market for more than fourteen years now, there is still a limited data on investigation of the assay and purity profile of ziprasidone in raw materials and pharmaceuticals. Determination of ziprasidone in pharmaceutical formulations has been performed by CE,${ }^{[3]}$ NP-HPTLC and RP-HPTLC. ${ }^{[4]}$ An HPLC method was reported for the determination of ziprasidone and its five impurities, ${ }^{[5]}$ and several stability-indicating methods for the determination of ziprasidone were reported using HPLC, ${ }^{[6,7]}$ UPLC,${ }^{[8,9]}$ TLC, ${ }^{[7]}$ and spectrofluorimetry. ${ }^{[10]}$

Reactivity of the alpha position of the benzoxindol moiety in the molecule of ziprasidone contributes to the instability of the molecule and to the formation of impurities and degradation products. The methylene moiety next to the lactam carbonyl is susceptible to nucleophiles and it can easily form an oxidative degradant (Impurity II; Figure 1). The carbonyl group in Impurity II is more reactive than a regular ketone group, owing to its activation by the neighboring lactam carbonyl group. Thus the oxidative degradant 
(Impurity II) can be involved in reaction of aldol condensation with molecule of ziprasidone when new degradant is formed ${ }^{[11]}$ (Impurity III; Figure 1). This reaction was observed in an injectable formulation containing sulfobutyl ether $\beta$-cyclodextrin (SBE $\beta C D)$ as a solubilizer of ziprasidone. Interaction of the cyclodextrin side chain with ziprasidone may facilitate oxidative degradation and a subsequent aldol condensation with another ziprasidone molecule. ${ }^{[12]} \mathrm{A}$ degradant which is formed at an ambient temperature under the influence of the daylight in the solid state ziprasidone is a product of the side reaction of benzisothiazol at the alpha position of the benzoxindol moiety of ziprasidone (Impurity V; Figure 1). Apart from the above mentioned impurities, the monographs of ziprasidone in the European Pharmacopoeia (EP) ${ }^{[13]}$ and the United States Pharmacopoeia (USP), ${ }^{[14]}$ and the ziprasidone manufacturers require testing the residues of the ziprasidone synthesis precusors (Impurity I and Impurity IV, respectively; Figure 1). Photostability of ziprasidone and photoisomerisation of the benzisothiazole moiety of ziprasidone were investigated by means of UHPLC-DAD/ESI-Q-TOF ${ }^{[15]}$ and LC-MS, ${ }^{[16]}$ respectively. So far, only one paper proposed a validated HPLC method for the determination of ziprasidone and its impurities in the pharmaceuticals,${ }^{[5]}$ while the other papers have reported on determination of ziprasidone in the presence of impurities resulting from the stability-indicating procedures.${ }^{[6-10]} \mathrm{A}$ stability indicating thin-layer chromatography was reported for the determination of ziprasidone in the presence of the synthesis precursors (Impurities I and IV). ${ }^{[7]}$

No reports are available on the thin-layer chromatographic method for the purity assessment of ziprasidone in pharmaceuticals, which has prompted us to develop and 
validate an alternative TLC method for the simultaneous determination of ziprasidone and its impurities using instrumental planar chromatography.

\section{EXPERIMENTAL}

\section{Materials}

Ziprasidone, (5-[2-[4-(1,2-benzisothiazol-3-yl)-1-piperazinyl]ethyl]-6-chloro-1,3dihydro-2H-indol-2-one); Impurity I (3-(1-piperazinyl)-1,2-benzisothiazole; Impurity II (5-[2-[4-(1,2-benzisothiazol-3-yl)-1-piperazinyl]ethyl]-6-chloro-1,3-dihydro-2H-indol2,3-dione); Impurity III (5,5'-bis[2-[4-(1,2-benzisothiazol-3-yl)-1-piperazinyl]ethyl]6,6'-dichloro-1,1',3,3'-tetrahydro-3-hydroxy-[3,3'-bi-2 $\mathrm{H}$-indole]-2,2'-dione); Impurity IV (6-chloro-5-(2-chloroethyl)-1,3-dihydro-2H-indol-2-one) and Impurity V (3-(1,2benzisothiazol-3-yl)-5-[2-[4-(1,2-benzisothiazol-3-yl)-1-piperazinyl]ethyl]-6-chloro-1,3dihydro-2H-indol-2-one) were kindly supplied by Pfizer Inc. (Groton, CT, USA). Zeldox (ziprasidone hydrochloride capsules, $40 \mathrm{mg}$, bach 710308135 and bach D10345242) and Zeldox (ziprasidone mesylate powder for the solution for injection $20 \mathrm{mg} \mathrm{mL}^{-1}$, bach 8274917) were manufactured by Pfizer (Illertissen, Germany, and Poce-sur-Cisse, France, respectively). All other reagents, i.e., toluene (POCH,Gliwice, Poland), methanol (J.T.Baker B.V., Deventer, Holland), concentrated hydrochloric acid and glacial acetic acid (Merck, Darmstadt, Germany) were of the analytical purity grade.

\section{Solutions}

\section{Standard Solutions}


Stock solutions of ziprasidone $\left(1 \mathrm{mg} \mathrm{mL}^{-1}\right)$ and impurities I, II and IV $\left(0.15 \mathrm{mg} \mathrm{mL}^{-1}\right)$ were prepared in methanol, while impurities III $\left(0.15 \mathrm{mg} \mathrm{mL}^{-1}\right)$ and $\mathrm{V}\left(0.15 \mathrm{mg} \mathrm{mL}^{-1}\right)$ were disolved in the mixture of methanol and $\mathrm{HCl}(0.001 \mathrm{~mL} \mathrm{HCl}$ in $10 \mathrm{~mL}$ methanol). Solution of Impurity III was stored for one day at $4^{\circ} \mathrm{C}$, and those of ziprasidone and the other impurities for 7 days, according to the earlier established stability periods valid for these solutions. Due to photosensitivity of ziprasidone, all the solutions were protected from light by storage in amber bottles, in order to prevent them from photodegradation. ${ }^{[5]}$

Six different solutions for the calibration curves were prepared by diluting the stock solutions with metanol in order to obtain concentrations from 0.01 to $0.07 \mathrm{mg} \mathrm{mL}^{-1}$ for ziprasidone, from 0.0025 to $0.015 \mathrm{mg} \mathrm{mL}^{-1}$ for impurities I, III, IV, and V, and from 0.0035 to $0.02 \mathrm{mg} \mathrm{mL}^{-1}$ for impurity II. The $10-\mu \mathrm{L}$ aliquots of each solution were applied on to the plates, which was equivalent to the ziprasidone amounts from 100 to $700 \mathrm{ng}$, the impurity I, III, IV, and V amounts from 25 to $150 \mathrm{ng}$, and the impurity II amounts from 35 to $200 \mathrm{ng}$.

\section{Sample Solutions}

The contents of ten capsules of ziprasidone were weighed and mixed. The quantity of the mixed content equivalent to $18 \mathrm{mg}$ ziprasidone and the quantity of the powder for the solution for injection equivalent to $18 \mathrm{mg}$ ziprasidone were transferred to the $10-\mathrm{mL}$ volumetric flasks, the entity was ultrasonicated in the $6 \mathrm{~mL}$ solvent $(0.001 \mathrm{~mL} \mathrm{HCl}$ in 10 $\mathrm{mL}$ methanol) for $10 \mathrm{~min}$, and then manually shaked for 15 more minutes. The solutions were made up to $10 \mathrm{~mL}$ with the same solvent, and then centrifuged at $3000 \mathrm{U} / \mathrm{min}$ for 15 
$\min$. The obtained supernatants were filtered through the 0.45 -mm pore size membrane filter (Millipore). For an assay of the impurities, the $10-\mu \mathrm{L}$ aliquots of the filtrates were applied to the chromatographic plates. For an assay of ziprasidone, the filtrated supernatants were diluted with methanol to the ziprasidone concentration of $0.5 \mathrm{mg} \mathrm{mL}^{-1}$ and the $1-\mu \mathrm{L}$ aliquots of these soultions were applied to the chromatographic plates.

\section{Chromatography}

Thin-layer chromatographic analyses were performed on the $10 \mathrm{~cm} \times 12 \mathrm{~cm}$ plates cut from the $20 \mathrm{~cm} \times 20 \mathrm{~cm}$ aluminium baked plates, precoated with silica gel $60 \mathrm{~F}_{254}$ (Merck, Darmstadt, Germany). Standard and pharmaceutical preparation samples were applied $10 \mathrm{~mm}$ above the lower edge of the plate, using the Linomat 5 application device (Camag, Muttenz, Switzerland). Samples were applied bandwise at the 6-mm band width, with an application rate of $10000 \mathrm{~nL}^{\mathrm{s}-1}$. An ascending development mode at ambient temperature was performed to the distance of $119 \mathrm{~mm}$ in the twin-trough TLC chamber presaturated for 15 min with mobile phase (toluene-methanol-glacial acetic acid, 7.5:0.5:0.5 v/v/v). After the development, the chromatographic plates were dried for 30 $\mathrm{min}$ at ambient air and once again developed to the distance of $119 \mathrm{~mm}$ in the freshly prepared mobile phase of the same composition as before, after the 15-min chamber presaturation. The dried chromatographic plates were scanned at the wavelengths of 250 and $320 \mathrm{~nm}$ by means of the Camag TLC Scanner II in the reflectance/absorbance mode.

\section{RESULTS AND DISCUSSION}


Significant difference in polarity of ziprasidone and its impurities has an impact on their retention, so that the official pharmacopoeial methods ${ }^{[13,14]}$ use two liquid chromatographic systems, one for the separation and purity assay of the early eluting impurities I and II, and the other for the late eluting impurities III and V. In our earlier investigations, we modeled the quantitative structure-retention relationship of the liquid chromatographic separation of ten compounds structurally related to ziprasidone, i.e., its impurities and metabolites, ${ }^{[17]}$ and developed a single liquid chromatographic system for the separation and purity assay of ziprasidone and its five impurities. ${ }^{[5]}$ One report described the development and validation of the HPLC and TLC methods for the determination of ziprasidone in the presence of three degradation products supplied by the manufacturer. ${ }^{[7]}$ The thin-layer chromatographic separation of ziprasidone and its degradants was carried out on the aluminium-backed sheets precoated with silica gel $60 \mathrm{~F}_{254}$ using chloroform-methanol-glacial acetic acid (7.5:0.5:0.45, v/v/v) as mobile phase. Using the same chromatographic system, in our present preliminary study we obtained separation of impurities I and II from ziprasidone, impurity III remained on the start line, and impurities IV and V co-eluted. Due to the toxicity of the halogenated aliphatic hydrocarbons (e.g., chloroform), Directive 1999/45/EC ${ }^{[18]}$ recommends avoiding its use. Based on the solvent selectivity properties clustered in the Snyder's solvent selectivity triangle with chloroform belonging to group VIII, we replaced it with two alternative solvents from the closest group VII, benzene and toluene. The satisfactory resolution of all investigated compounds was obtained with the mixture benzenemethanol-glacial acetic acid $(6.3: 0.5: 045, \mathrm{v} / \mathrm{v} / \mathrm{v})$, yet due to the same safety reason, benzene had to be replaced by toluene. This second replacement needed minor 
modification of the mobile phase component ratio and the final composition of toluenemethanol-glacial acetic acid (7.5:0.5:0.5 v/v/v) resulted in good separation of all components. The migration distances were $18.9 \pm 0.37 \mathrm{~mm}, 27.7 \pm 0.28 \mathrm{~mm}, 30.5 \pm 0.32$ $\mathrm{mm}, 41.7 \pm 0.45 \mathrm{~mm}, 58.42 \pm 0.36 \mathrm{~mm}$ and $69.8 \pm 0.86 \mathrm{~mm}$, for impurity III, impurity I, impurity II, ziprasidone, impurity V and impurity IV, respectively. The elution order of the separated compounds was driven by an increasing lipophilicity thereof (the $\log \mathrm{P}$ values for impurity I, impurity II, ziprasidone, and impurity V were equal to 3.0, 4.26, 4.67, and 7,44, respectively). Lipophilicity was calculated with use of the Chem Draw Ultra program (Cambridge, MA, USA). Exceptions in the elution order were Impurity III with the highest $\log \mathrm{P}$ value (8.51) and Impurity IV with the lowest $\log \mathrm{P}$ value (2.24). Impurity III with two piperazine moieties in its structure strongly binds to the silanol groups on the silica gel surface, which results in the lowest migration distance. Impurity IV which lacks piperazine moiety has the weakest retention and hence, the highest migration distance. Densitometric scans of the TLC chromatograms are shown in Fig 2. Testing the elaborated mobile phase upon the HPTLC and TLC glass-backed plates, it was shown that no better resolution was obtained than on the aluminium-backed and silica gel 60F precoated ones, which were then used for further validation of the developed method.

The in situ spectra were recorded for all investigated substances and they are shown in Fig. 3. Quantitative evaluation of impurities I, II, III and ziprasidone were performed at the wavelength $\lambda=320 \mathrm{~nm}$, and that of impurities IV and $\mathrm{V}$, at the wavelength $\lambda=250$ 
$\mathrm{nm}$. When scanning the chromatograms at $320 \mathrm{~nm}$, the lower baseline noise was observed.

The response (peak area) was proportional to the concentration (the amount applied to the plate) over the entire concentration ranges tested. The results referring to the elaborated calibration curves for ziprasidone and its five impurities are summarized in Table 1.

An effect of larger amounts of ziprasidone on the peak shape and the resolution of the impurities also had to be evaluated in order to avoid systematic errors. Therefore the accuracy of the method was estimated by determination of all impurities in the presence of ziprasidone. It was observed that high quantitative excess of ziprasidone results in poor resolution of Impurity I and II after the second development run and therefore the purity assay for Impurities I, II, III, and ziprasidone was performed after the first development run. Quantitative evaluation of Impurity IV and V was performed after the repeated second development run using the same mobile phase, which provided better resolution of these two impurities. A content of the capsules of ziprasidone $\left(1.80 \mathrm{mg} \mathrm{mL}^{-1}\right)$ were spiked with impurities I, III, IV and V at the concentrations of $0.0029,0.0036$, and $0.0054 \mathrm{mg} \mathrm{mL}^{-1}$ each (corresponding to $0.16,0.20$, and $0.30 \%$ ), and with Impurity II at the concentrations of $0.0043,0.0054$, and $0.0081 \mathrm{mg} \mathrm{mL}^{-1}$ (corresponding to $0.24,0.30$, and $0.45 \%$ ). Higher values of the limits for Impurity II (oxidation product of ziprasidone) were required due to the manufacturer's specification for dosage formulations. 
Densitograms obtained from the spiked samples of ziprasidone are shown in Fig. 4. No interference from the capsules excipients and the residual impurities were observed. Calculated recoveries were plotted against the expected values (corresponding to the standards without ziprasidone). Recoveries and the relative standard deviation values for all impurities were acceptable for a purity method (Table 2). The accuracy acceptance criteria for the drug impurity testing depend on impurity levels. For the levels below $0.50 \%$ and those above $0.50 \%$, the recovery rates of $80-120 \%$ and $90-110 \%$, respectively, and the RSD values of $10 \%$ and 5\%, respectively, are acceptable. ${ }^{[19]}$

The repeatability of the method was assessed by running replicate applications $(n=6)$ of ziprasidone and Impurities I-V at the three concentrations, with the relevant statistical parameter and the results are listed in Table 3.

The limit of detection (LOD) and the limit of quantification (LOQ) were determined by fitting the back-calculated inter-day standard deviation for each calibration standard. The $\mathrm{y}$-intercept was equal to $\mathrm{SD}_{0}$ (the estimated standard deviation at a zero concentration). The LOD was defined as $3 \mathrm{SD}_{0}$, and the LOQ was defined as $10 \mathrm{SD}_{0}$. The LOD values for Impurities I-V were established as equal to $7.1,8.6,8.4,2.5$, and $11.0 \mathrm{ng}$, respectively (equivalent to the percentage impurity levels of $0.04,0.05,0.08,0.01$, and $0.06 \%$, respectively). The LOQ values for Impurities I-V were established as equal to 23.7, 28.0, 28.0, 8.5, and $36.7 \mathrm{ng}$, respectively (equivalent to the percentage impurities levels of $0.13,0.16,0.27,0.05$, and $0.20 \%$, respectively). The experimentally obtained LOQ 
values for Impurities I-V were equal to $25 \mathrm{ng}$ per band (corresponding with the impurity level of $0.14 \%$ ).

Robustness is a measure of the capacity of the method to remain unaffected by small yet deliberate variations of the method working parameters, and it is an indications of the reliability of the method. ${ }^{[20,21]}$ In the course of the robustness tests, the effects of different amounts of toluene $( \pm 3 \%)$ and acetic acid $( \pm 2 \%)$ in mobile phase, and differences in the developing distances $(11$ and $13 \mathrm{~cm})$ and the band widths $(5$ and $7 \mathrm{~mm})$ were examined. Based on the obtained results, no significant resolution changes between ziprasidone and its impurities was observed, showing that the proposed method remains unafected by small variations of experimental conditions.

The method was used to screen three samples of ziprasidone, i.e., the Zeldox ${ }^{\circledR}$ powder for the solution for injection $\left(20 \mathrm{mg} \mathrm{mL}^{-1}\right)$ with the expired validity date (August, 2011), the Zeldox ${ }^{\circledR}$ capsules (40 mg, batch 710308135) with the expired validity date (August, 2011), and the Zeldox ${ }^{\circledR}$ capsules (40 mg, batch D10345242) valid until September, 2017. The chromatograms of the tested samples are shown in Fig. 4. The contents of ziprasidone in the capsule, batch 710308135, in the sample powder for the solution (both samples with the expired validity dates), and in the valid capsules, batch D10345242, were established as equal to $98.8 \pm 0.62 \%, 99.6 \pm 0.54 \%$, and $97.7 \pm 0.57 \%$, respectively, and in that way all three formulations met the requirements of label declaration. In each case, the content of impurities was below of the LOQ value, i.e., below $0.14 \%$. 


\section{CONCLUSION}

The results obtained suggest that TLC is an efficient method for the separation and quantitative determination of ziprasidone and its main impurities. The method is sensitive at the $n g$ level, as well as its precision and reproducibility is satisfactory. The simple chromatographic system can be used as an alternative method for the purity screening of ziprasidone in pharmaceutical formulations.

\section{ACKNOWLEDGMENTS}

This work was supported by the Ministry of Science and Technological Development of the Republic of Serbia, Contract No. 172033.

\section{REFERENCES}

1. Lemke, T.L.; Williams, D.A.; Roche, V.F.; Zito, S.W. Foye’s Principles of Medicinal Chemistry, 7th Ed., Lippincot Williams \& Wilkins, Baltimore 2012, 449-484.

2. Greenberg, W.M.; Citrome, L. Ziprasidone for schizophrenia and bipolar disorder: a review of the clinical trials. CNS Drug Rev. 2007, 13, 137-177.

3. Farina, C.; Kremser, L.; Raggi, M.A.; Kenndler E. Determination of Ziprasidone in pharmaceutical formulations by capillary zone electrophoresis. J. Pharm. Biomed. Anal. 2008, 46, 471-476.

4. Skibinski, R.; Komsta, L. Validation of NP-HPTLC and RP-HPTLC methods with videodensitometric detection for analysis of ziprasidone in pharmaceutical formulations. J. Planar. Chromatogr-Mod. TLC 2010, 23, 23-27. 
5. Pavlovic, M.; Malesevic, M.; Nikolic, K.; Agbaba, D. Development and Validation of an HPLC Method for Determination of Ziprasidone and Its Impurities in Pharmaceutical Dosage Forms. J. AOAC Int. 2011, 94, 713-722.

6. Singh, A.; Rao, B.M.; Desphie, G.R.; Sangaraju, S.; Srinivasu, M.K.; Devi, M.L.; Satyanarayana, P.V.V.; Chirasekhar, K.B. A Rapid Stability-Indicating LC Method for Ziprasidone Hydrochloride. Chromatographia 2007, 65, 191-196.

7. El-Sherif, Z.A.; El-Zeany, B.; El-Houssini, O.M.; et al. Stability indicating reversedphase high-performance liquid chromatographic and thin layer densitometric methods for the determination of ziprasidone in bulk powder and in pharmaceutical formulations. Biomed. Chromatogr. 2004, 18, 143-149.

8. Zakowiecki, D.; Cal, K. Development of rapid and robust stability-indicating mthod for analysis of ziprasidone (hydrochloride and freebase|) as drug substance and in medicines by UPLC. Acta Poloniae Pharmaceutica-Drug Research 2012, 69, 809-819. 9. Ray, S.; Kumari, S.K.; Krishnaiah, C.; Rao, N.A. Development of a StabilityIndicating UPLC Method for Determination Ziprasidone Hydrochloride and Its Associated Degradation Products Present in Active Pharmaceutical Ingradients and Pharmaceutical Dosage Forms, J. Liq. Chromatogr. Relat. Technol. 2013, 36, 968-982. 10. Mohamed, I.; Belal, W.F., El-Enany, N.; Eid, M.; El-Shaheny, R.N. StabilityIndicating Spectrofluorimetric Method for the Assay of Ziprasidone in Capsules. $J$.

Fluoresc. 2011, 21, 1659-1667.

11. Li, M. Organic Chemistry of Drug Degradation, RSC Publishing, 2012, 124-126. 
12. Hong, J.; Shah, J.C.; Mcgonagle, M.D. Effect of Cyclodextrin Derivation and Amorphous State of Complex on Accelerated Degradation of Ziprasidone. J. Pharm. Sci. 2011, 100, 2703-2716.

13. European Pharmacopoeia, 8th ed.; Council of Europe; Strasbourg, France, 2014. 14. United States Pharmacopoeia, 38NF-33. US Pharmacopeia Convention; Rockville, MD, 2015.

15. Skibinski, R. Photostability Study and Identification of Photodegradation Products of Ziprasidone by UHPLC-DAD/ESI-Q-TOF. J. Liq. Chromatogr. Relat. Technol. 2012, 35, 2097-2012.

16. Sharp, T.R.; Leeman, K.R.; Bryant, D.E.; Horan, G.J. On the photoisomerization of the benzisothiazole portion of ziprasidone. Tetrahedron Lett. 2003, 44, 1559-1561.

17. Nikolic, K.; Pavlovic, M.; Smoliński, A.; Agbaba, D. The Chemometric Study and Quantitative Structure Retention Relationship Modeling of Liquid Chromatography Separation of Ziprasidone Components. Comb. Chem. High. T. Scr. 2012, 15, 730-744. 18. Directive 1999/45/EC of the European Parliament and of the Council, Official Journal, 1999, 200, 1-68.

19. Ferenczi-Fodor, K.; Vegh, Z.; Nagy-Turak, A.; Renger, B.; Zeller, M.J. Validation and quality assurance of planar chromatographic procedures in pharmaceutical analysis. J. AOAC Int. 2001, 84, 1265-1276.

20. ICH harmonized guideline: validation of analytical procedures: text and methodology Q (R1), Geneva, 2005. 
21. Renger, B.; Végh, Z.; Ferenczi-Fodor, K. Validation of thin layer and high performance thin layer chromatographic methods. J. Chromatogr. A 2011, 13, 27122721. 
Table 1. The parameters $a$ and $b$ of the calibration curve $(\mathrm{y}=a \mathrm{x}+b)$ and the respective numerical values of standard deviation (SD) and correlation coefficient (r) for standard samples of ziprasidone and its impurities I, II, III, IV, and V

\begin{tabular}{|l|l|l|l|l|l|}
\hline Compound & $\begin{array}{l}\text { Concentration } \\
\text { range ng band }^{-1}\end{array}$ & $a$ & $b$ & SD & $r$ \\
\hline Ziprasidone & $100-700$ & 1.030 & 60.158 & 5.779 & 0.9996 \\
\hline Impurity I & $25-150$ & 2.507 & 93.950 & 5.934 & 0.9988 \\
\hline Impurity II & $35-200$ & 1.600 & 29.837 & 4.574 & 0.9992 \\
\hline Impurity III & $25-150$ & 2.236 & 41.530 & 6.260 & 0.9925 \\
\hline Impurity IV & $25-150$ & 3.237 & 9.567 & 2.756 & 0.9998 \\
\hline Impurity V & $25-150$ & 8.030 & -305.892 & 29.448 & 0.9968 \\
\hline
\end{tabular}


Table 2. The parameters which characterize the accuracy of the method for standard samples of ziprasidone and its impurities I, II, III, IV, and V

\begin{tabular}{|c|c|c|c|}
\hline Compound & Level (\%) & $\begin{array}{l}\text { Mean recovery }(\%) \\
\mathrm{n}=3\end{array}$ & RSD (\%) \\
\hline \multirow[t]{3}{*}{ Ziprasidone } & 80 & 99.50 & 1.50 \\
\hline & 100 & 99.80 & 1.30 \\
\hline & 120 & 95.75 & 0.95 \\
\hline \multirow[t]{3}{*}{ Impurity I } & 0.16 & 95.88 & 3.41 \\
\hline & 0.20 & 97.59 & 3.94 \\
\hline & 0.30 & 94.94 & 3.10 \\
\hline \multirow[t]{3}{*}{ Impurity II } & 0.24 & 97.12 & 2.90 \\
\hline & 0.30 & 96.64 & 3.97 \\
\hline & 0.45 & 98.31 & 2.76 \\
\hline \multirow[t]{3}{*}{ Impurity III } & 0.16 & 102.58 & 8.71 \\
\hline & 0.20 & 97.16 & 5.35 \\
\hline & 0.30 & 105.30 & 7.42 \\
\hline \multirow[t]{3}{*}{ Impurity IV } & 0.16 & 103.77 & 2.23 \\
\hline & 0.20 & 104.33 & 3.27 \\
\hline & 0.30 & 96.84 & 5.05 \\
\hline \multirow[t]{3}{*}{ Impurity V } & 0.16 & 103.40 & 1.86 \\
\hline & 0.20 & 100.07 & 1.85 \\
\hline & 0.30 & 106.66 & 1.84 \\
\hline
\end{tabular}


Table 3. The parameters which characterize the precision of the method $(n=6)$ for standard samples of ziprasidone and its impurities I, II, III, IV, and V

\begin{tabular}{|l|l|l|l|l|l|l|}
\hline Amount & Ziprasidone & Impurity I & Impurity II & Impurity III & Impurity IV & Impurity V \\
ng band & RSD (\%) & RSD (\%) & RSD (\%) & RSD (\%) & RSD (\%) & RSD (\%) \\
\hline 100 & 1.41 & & & & & \\
\hline 300 & 0.81 & & & & & \\
\hline 500 & 0.41 & & & & & \\
\hline 29 & & 2.94 & & 8.45 & 2.37 & 2.84 \\
\hline 36 & & 1.69 & & 3.37 & 3.02 & 2.11 \\
\hline 54 & & 0.97 & & 6.83 & 2.67 & 1.99 \\
\hline 43 & & & 2.98 & & & \\
\hline 54 & & & 3.75 & & & \\
\hline 81 & & & 2.16 & & & \\
\hline
\end{tabular}


Figure 1. Chemical structures of ziprasidone and its impurities
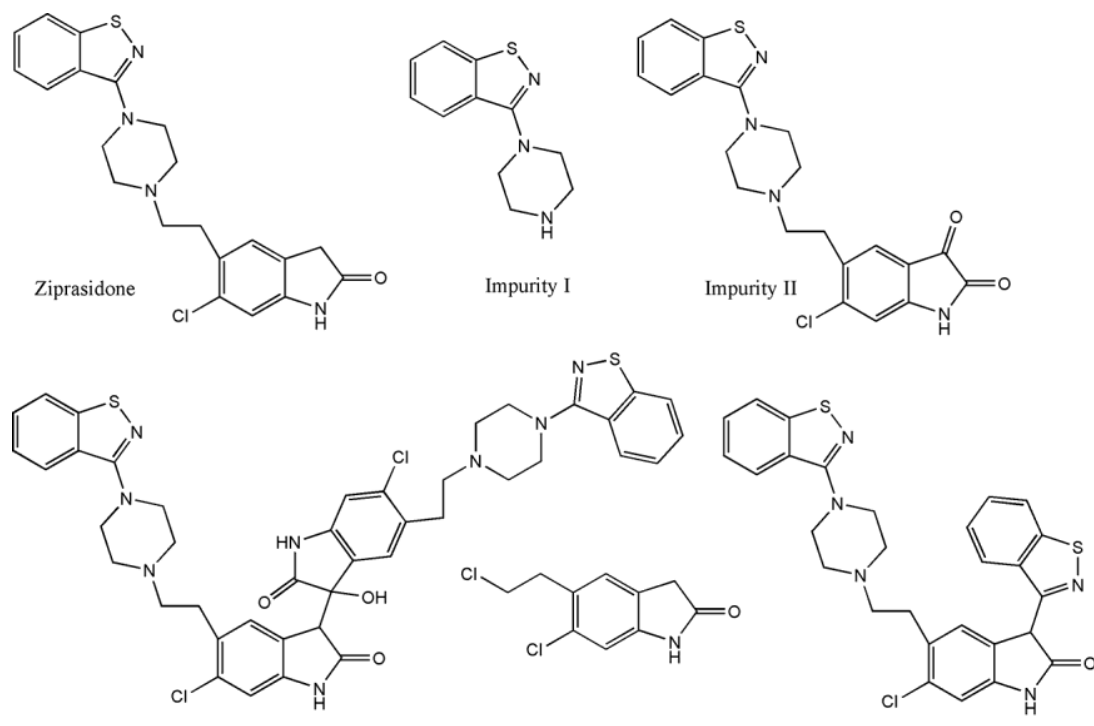

Impurity III

Impurity IV

Impurity $\mathrm{V}$

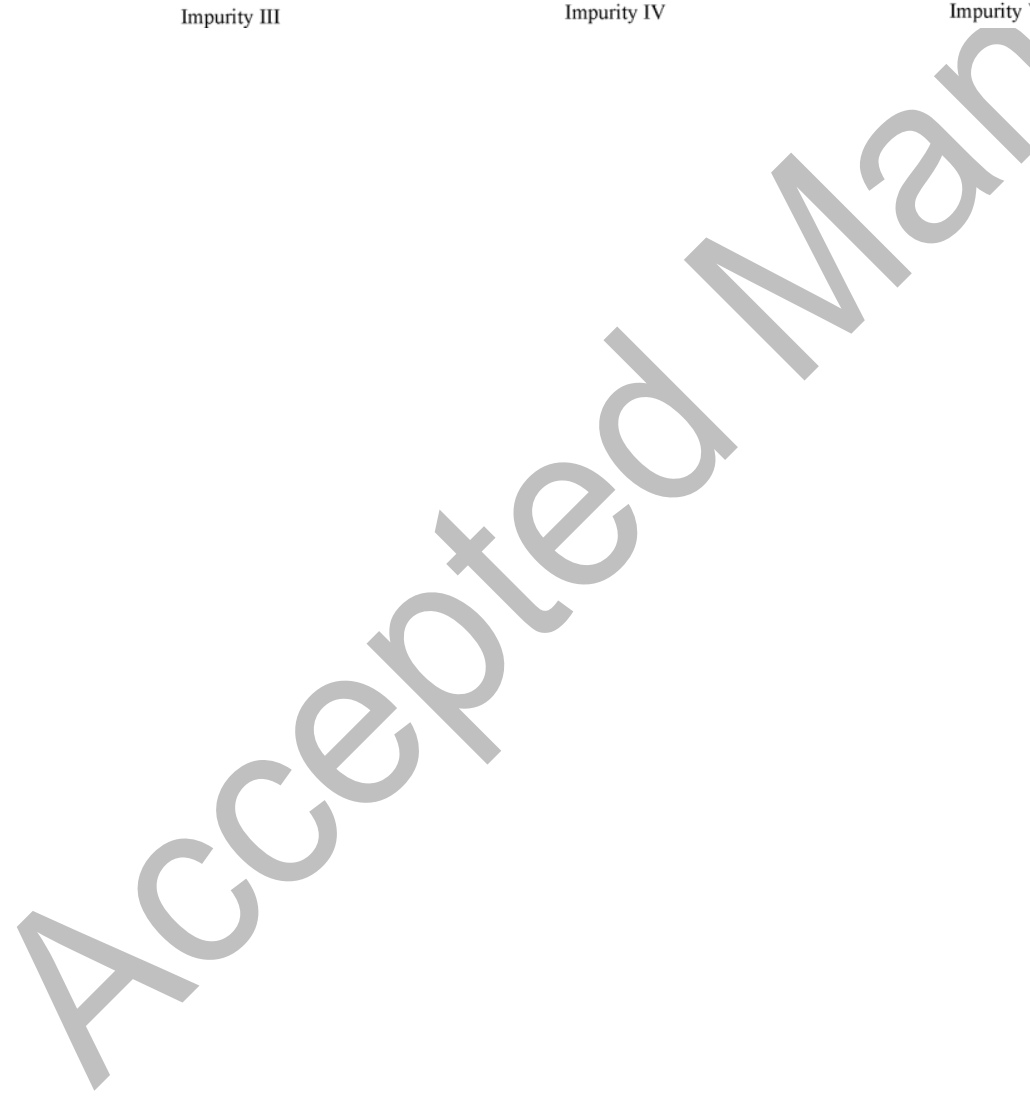


Figure 2. Densitogram obtained from a test mixture of ziprasidone and its impurities

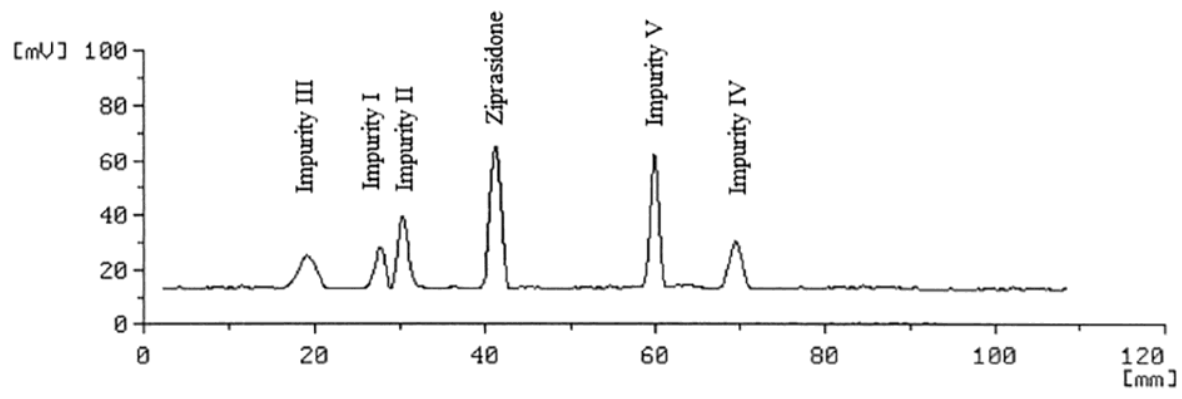


Figure 3. The in situ UV spectra of ziprasidone (4) and its Impurities (Impurity I (1), Impurity II (2), Impurity III (3), Impurity IV (6) and Impurity V (5)).

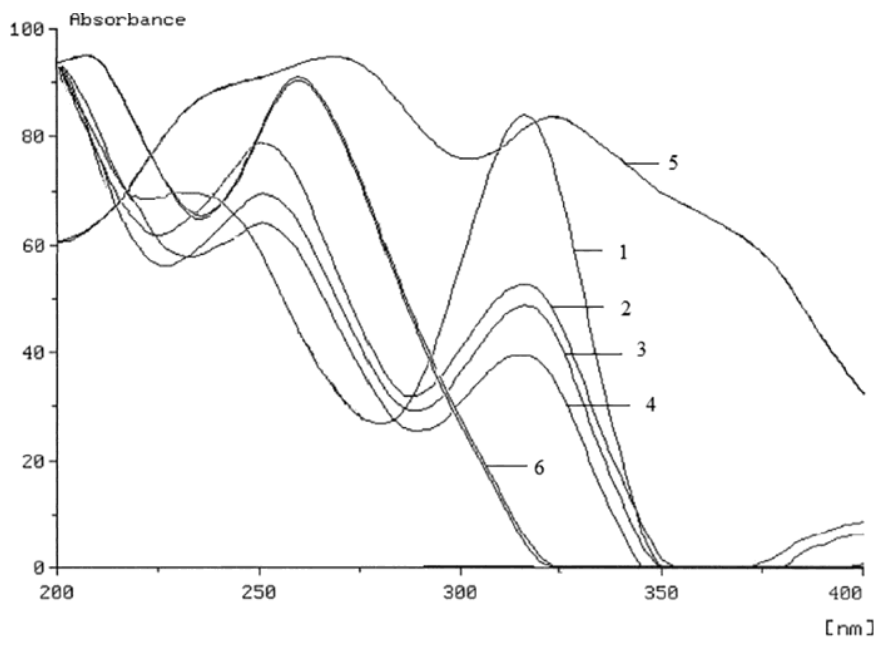


Figure 4. Densitograms recorded at the wavelength $\lambda=320 \mathrm{~nm}$ after the first development run (A) and at the wavelength $\lambda=250 \mathrm{~nm}$ after the second development run (B) for (a) the sample of the ziprasidone without impurities; (b,d) standards of Impurities I, III, IV and V corresponding to the impurity levels 0.16 and $0.20 \%$ and standard of Impurity II corresponding to the impurity levels 0.24 and $0.30 \%$; $(\mathrm{c}, \mathrm{e})$ the ziprasidone sample spiked with Impurities I, III, IV and V corresponding to the impurity levels 0.16 and $0.20 \%$ and standard of Impurity II corresponding to the impurity levels 0.24 and 0.30\%; (f,g,h) Zeldox ${ }^{\circledR}$ capsules, 40 mg, batch 710308135, Zeldox® capsules, 40 mg, batch D10345242, and Zeldox® powder for the solution for injection, batch 8274917. Peaks 1-6 correspond to Impurity III, I, II, ziprasidone, Impurity V and IV, respectively. At the migration distance of $48.5 \mathrm{~mm}$, an unknown peak is observed.

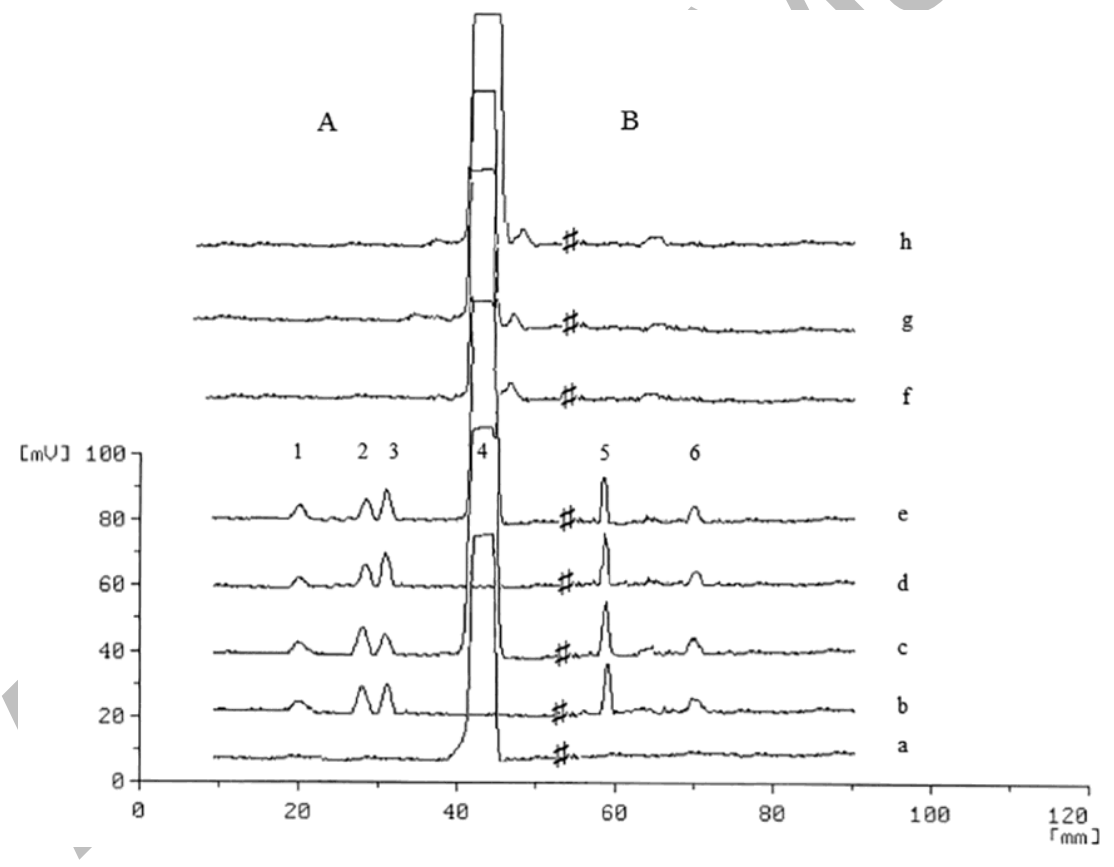

